\title{
Do the national performance tables really indicate the performance of accident and emergency departments?
}

\author{
June A Edhouse, Jim Wardrope
}

\begin{abstract}
Objective-To determine the current practice of nurse triage in accident and emergency departments in England, and to examine the relation between triage systems and performance in the Department of Health comparative performance guide. Design-A postal questionnaire was sent to all consultants in accident and emergency medicine in England.

Results-151 responses were analysed, representing $72 \%$ of the departments seeing at least 15000 new patients annually. Triage systems vary widely throughout departments, ranging between advanced triage, partial triage, and "eyeballing". There is no standardisation of the process or duration of triage. There appears to be no standard method of measuring the time to immediate assessment. There is no correlation between the quality of initial assessment and performance in the tables.

Conclusions-The national performance figures do not correlate with the quality of the initial assessment; comparisons based on these figures are therefore misleading. More effective performance indicators are available, which would provide a truer indication of the quality of accident and emergency services.
\end{abstract}

( $\mathcal{F}$ Accid Emerg Med 1996;13:123-126)

Key terms: patient's charter; immediate assessment; quality standards; triage

The Patient's Charter states that a patient should be seen immediately they arrive in the department, and their need for treatment assessed. ${ }^{1}$ Department of Health guidelines define "immediately" as being within five minutes of arrival, without the patient having to go through other procedures first. "Assessment" has no strict definition. The guidelines state that full triage is not necessary; more important is the patient's perception that they have been dealt with speedily and effectively.

The Department of Health comparative performance guide ${ }^{2}$ uses the time to immediate assessment as the indicator to compare performance between accident and emergency (A\&E) departments. The comparative performance guide claims to provide detailed information in order that the public can make informed decisions about their health care.
In order to qualify for inclusion in the performance tables, a survey of at least $5 \%$ of new patients attending in a three month period had to be performed. The guidelines stipulate that time of arrival must be the time the patient first enters the department. Where the Audit Commission's auditors judged the data collection systems to be satisfactory, star ratings have been allocated. Only 186 units have been awarded a star rating. The star ratings are presented in the form of league tables, and claim to "show performance at a glance". One star means that less than $80 \%$ of patients were assessed immediately they arrived in the department, two stars mean $80-84 \%$, three stars $85-90 \%$, four stars $90-94 \%$, and five stars $95 \%$ or more.

Nurse triage has become increasingly popular in A\&E departments throughout the United Kingdom. Triage originates from the French word meaning to pick, sort or select. Within the context of accident and emergency medicine it is the process by which a patient is assessed upon arrival in the department and classified according to the urgency of the problem. Patients are then treated according to priority, rather than on a "first come, first served" basis. There are various types of triage $^{3}$; in the United Kingdom triage systems can generally be classified as non-professional, basic, or advanced.

The non-professional triage function is generally carried out by the receptionist, and though commonly employed in the past, few would advocate its continued use today.

Basic triage is carried out by a trained nurse, but there is no strict definition of the term, and systems vary widely between departments. At its most elementary level, the triage nurse might sit at the reception desk, or at a desk in the waiting room; the nurse greets the patient and "eyeballs" the patient's condition, and then directs them to the waiting room or trolley area as appropriate. Alternatively, the nurse may be located in a dedicated triage room, where a brief history can be taken, essential first aid performed, and the patient directed to the waiting area.

Advanced triage is performed by a qualified nurse who has usually received some special training. The patient is assessed in private; the assessment includes a detailed history, examining the patient, performing first aid, and making notes form part of the patient's permanent record. 
Methods

A postal questionnaire was sent to all consultants in accident and emergency medicine in England. The questionnaires were completed anonymously. The questionnaire asked the following questions:

(1) The number of new patients attending per year

(2) The type of triage system in operation, that is, basic, advanced, etc

(3) The number of hours per week during which formal triage takes place

(4) Are patients registered before triage or after triage?

(5) Is there is a single triage nurse for all patients, or does the triage nurse see only the walking wounded, trolley patients being assessed by other staff in the department?

(6) The definition time of arrival in the department

(7) Definition of time to immediate assessment, that is, the time the patient is "eyeballed", or the time taken to formally triage the patient

(8) The method used to collect the data, and the sample size

(9) The star rating awarded in the comparative performance guide

(10) The extra nursing resources deployed in the department in order to perform immediate assessment

Of the 405 questionnaires sent, 213 were returned. Twelve questionnaires were discounted because they had been inadequately completed. The responses were analysed by department, not by individual consultant. Where two questionnaires were returned from the same department, one was discarded. Departments seeing less than 15000 patients per year were excluded.

One hundred and fifty one departments were included in the analysis; this represents $72 \%$ of the departments who see at least 15000 new patients annually.

\section{Results}

Of the 151 departments analysed, 146 gave details of their performance in the published league tables: 89 departments $(61 \%)$ were awarded a star rating, while 57 (39\%) were not. In the national performance tables, $186 / 268$ NHS Trusts or directly managed hospitals were awarded a star rating (69\%), while $82 / 268$ $(30 \%)$ were not.

The results for each question are divided into two sections, the first examining the process of immediate assessment as it is carried out, and the second examining the effect of the variable on performance as given by the national performance figures.

\section{DEFINITION OF TRIAGE}

Process

In 81 departments full triage took place. The nurse took a history, performed a limited examination, gave first aid, and made notes. In 49 departments, however, the nurse might only greet the patient, take a brief history,
Table 1 Definition of triage

\begin{tabular}{lc}
\hline Type of triage & No of departments \\
\hline Full triage & 81 \\
"Eyeballing" & 10 \\
Partial triage & 49 \\
Mixture & 8 \\
Not stated & 3 \\
Total & 151 \\
\hline
\end{tabular}

and perform appropriate first aid, without examining the patient or taking notes. The results are summarised in table 1 .

\section{Performance}

The star rating of those departments performing full triage were compared with the performance figures of departments practising other types of triage. The quality of triage performed is not reflected in the star ratings. Departments performing advanced triage are just as likely to achieve a low star rating (14 out of 81 departments scoring one star) as departments who operate more basic triage systems (four out of 70 departments scoring one star). The results are summarised in table 2 .

\section{DURATION OF TRIAGE}

Process

In all, 150 departments supplied details of the number of hours during which they operated formal triage: 98 departments performed triage continuously for 24 hours a day, 7 days a week; 35 departments practised triage for 12 hours each day, 7 days a week; in the remaining 17 departments, there was a variety of times during which triage occurred.

\section{Performance}

There was no obvious correlation between the performance of those departments operating continuous triage, 24 hours a day, and those operating triage for 12 hours a day. It is surprising to note that 10 departments operating triage for 12 hours a day scored four or five stars. Table 3 summarises the results.

Table 2 Relation between triage system and performance

\begin{tabular}{lcc}
\hline Star rating & No of departments & \\
\cline { 2 - 3 } & Full triage & Other \\
\hline 5 & 9 & 11 \\
4 & 13 & 10 \\
3 & 7 & 8 \\
2 & 5 & 8 \\
1 & 14 & 4 \\
0 & 31 & 26 \\
Not known & 2 & 3 \\
Total & 81 & 70 \\
\hline
\end{tabular}

Table 3 Relation between duration of triage and performance

\begin{tabular}{llcc}
\hline Star rating & \multicolumn{3}{l}{ No of departments } \\
\cline { 2 - 4 } & 24 h triage & 12 h triage & Other \\
\hline 5 & 14 & 3 & 3 \\
4 & 16 & 7 & 0 \\
3 & 6 & 7 & 2 \\
2 & 7 & 4 & 3 \\
1 & 13 & 2 & 8 \\
0 & 37 & 12 & 0 \\
Not known & 5 & 0 & 18 \\
Total & 98 & 35 & \\
\hline
\end{tabular}


TIME OF ARRIVAL

Process

The time interval used to measure time to immediate assessment appears to vary. Ninety six departments claimed that they use the time interval between registration and triage as the time to immediate assessment, that is, they use the time the patient registers as "time of arrival", rather than the time the patient enters the department. The Department of Health guidelines state that time of arrival must mean the time the patient walks through the doors of the department. In spite of this, 57 of these departments have been awarded a star rating.

\section{Performance}

Performance did not appear to differ, whichever method was used to measure the time interval between arrival and triage. This directly contradicts the Department of Health's own guidelines, and if this is a true representation of events it renders the performance tables meaningless. Clearly, if the data forming the basis of the star rating system are flawed, any conclusions based on these data would be statistically invalid, and that obviously includes some of the results of this study (see table 4).

\section{MEANING OF IMMEDIATE ASSESSMENT}

Process

The time to immediate assessment was defined as time to "eyeballing" in 33 departments, time to triage in 39 departments, and a mixture of these in 68 departments.

\section{Performance}

The different interpretations of time to immediate assessment do not appear to affect the star ratings achieved (see table 5).

EXTRA NURSING RESOURCES

Sixty six of the 151 departments have been allocated extra resources in order to fulfil the Patient's Charter standards with respect to

Table 4 Relation between time of arrival and performance

\begin{tabular}{lcccl}
\hline Star rating & \multicolumn{3}{l}{ No of departments } & \\
\cline { 2 - 5 } & $\begin{array}{l}\text { Time enters } \\
\text { dept }\end{array}$ & $\begin{array}{l}\text { Time of } \\
\text { registration }\end{array}$ & Other & $\begin{array}{l}\text { Not } \\
\text { stated }\end{array}$ \\
\hline 5 & 8 & 10 & 2 & 0 \\
4 & 5 & 17 & 1 & 0 \\
3 & 3 & 9 & 3 & 0 \\
2 & 2 & 8 & 3 & 0 \\
1 & 5 & 13 & 0 & 0 \\
0 & 17 & 35 & 0 & 4 \\
Not known & 1 & 4 & 10 & 4 \\
Total & 41 & 96 & &
\end{tabular}

Table 5 Relation between time to immediate assessment and performance

\begin{tabular}{lcccc}
\hline Star rating & \multicolumn{4}{l}{ No of departments } \\
\cline { 2 - 5 } & $\begin{array}{l}\text { Time to } \\
\text { eyeballing }\end{array}$ & $\begin{array}{l}\text { Time to } \\
\text { triage }\end{array}$ & Mixture & $\begin{array}{l}\text { Not } \\
\text { stated }\end{array}$ \\
\hline 5 & 5 & 7 & 7 & 2 \\
4 & 5 & 4 & 14 & 1 \\
3 & 3 & 0 & 11 & 0 \\
2 & 0 & 5 & 7 & 1 \\
1 & 2 & 7 & 8 & 1 \\
0 & 16 & 14 & 20 & 2 \\
Not known & 2 & 2 & 1 & 4 \\
Total & 33 & 39 & 68 & 11 \\
\hline
\end{tabular}

immediate assessment. It is unclear how many of these departments were allocated the extra money as a direct result of their poor performance figures and how many received the extra investment before the publication of the figures. The majority of these departments quoted a specific figure. The total amount of money being used in this financial year to improve the star ratings of these 66 departments is approximately 2.6 million pounds.

TRIAGE MODEL, DUTIES OF THE TRIAGE NURSE, AND SAMPLE SIZE

In 96 departments the patient registered at the reception desk before seeing the triage nurse, while in 46 departments the triage nurse assessed the patient before registration; the remainder used some other model. There was no difference in the performance figures of the three groups.

In 98 departments, the triage nurse assessed only walking wounded patients, while in 27 departments a single triage nurse assessed both walking wounded and trolley cases. There was little difference in performance between the various models.

Thirty three departments claimed they used a $100 \%$ patient sample, while the remaining departments used a variety of sample sizes. The results showed little difference in performance, no matter what the sample size.

\section{Discussion}

This study shows the huge variety of triage systems in operation. Advanced triage systems provide a higher quality of assessment than the more basic systems. Several studies have shown that nurse triage, by providing early contact with a qualified person, leads to a reduction in the levels of anxiety of patients and their companions, ${ }^{45}$ but a more recent study does not confirm this. ${ }^{6}$ However, the storm of correspondence ${ }^{7-12}$ which followed the publication of the study by George et $a l^{6}$ shows that many A\&E staff clearly believe that their triage systems are worthwhile.

Studies have shown that the average length of time taken to perform advanced triage is over six minutes. ${ }^{3}$ Reducing the initial assessment process down to its most basic level, that is, "eyeballing" the patients, in order to achieve good performance figures, may seriously compromise the quality of the assessment. Ambulance patients should all be assessed within a short time of their arrival in the department. Initial assessment of the walking wounded should be performed carefully and accurately, since patients assigned a low priority may wait two or three hours to see a doctor. The nurse needs time to inform the patient of their priority status, and the length of time they might expect to wait. The nurse can be held accountable for any judgements made. ${ }^{13} \mathrm{~A}$ triage decision is part of the patient's total care; therefore brief but accurate documentation is essential, both from a medicolegal standpoint and to aid communication with other departmental staff. If triage is to be performed to a reasonable 
standard, the process cannot always be accomplished within a minute or so.

The Patient's Charter has made some form of assessment mandatory, and departments are under managerial pressure to assess patients quickly in order to achieve high performance figures. There is no evidence that merely "eyeballing" a patient, a process that may involve only the briefest contact between patient and nurse, leads to any reduction in patient anxiety or increase in patient satisfaction. There is also a lack of evidence of any clinical benefit if triage of ambulant patients occurs within five, six, or even 10 minutes of the patient entering the department. It would appear that the star rating system is based on purely arbitrary numerical standards.

It is clear that a high star rating does not reflect the quality of the assessment process, merely the speed with which it is performed. As has been demonstrated, "assessment" encompasses a vast range of different systems, each of differing quality. Five star departments are not necessarily providing a better quality service than one star departments; in fact in some cases the reverse may be true. A department that compromises quality for the sake of speed may score a high star rating.

In some departments the pressure to score a high star rating is interfering with their well established advanced triage systems. Some departments are now running formal triage in parallel with an immediate assessment system. The nurse performing immediate assessment literally greets the patient, eyeballing their condition, and thus satisfies the Patient's Charter standard. Then, aware that this is an inadequate form of assessment, a second nurse performs formal triage in an unhurried way.

The Patient's Charter was intended to be implemented with no accompanying increase in resources. This study has shown that many departments are deploying significant resources in order to achieve a good star rating. While investment in triage is to be welcomed, we must question the use of scarce resources in order to achieve a good star rating.

This study also brings to light apparent problems with the reliability of the data which form the basis of the national performance figures. It appears that different measures are being used for the most fundamental pieces of data, for example the time of arrival in the department.

The comparative performance tables have been referred to as "league tables". Sporting league tables are never compiled using the results of the first five minutes of a match. It is difficult to justify using the events of the first five minutes in the department as an indicator of the quality of the whole process of care. Other standards exist which measure the efficiency of an A\&E department; time to see a doctor is one possible measure and this information is already routinely collected.

Time to admission to a hospital bed is not only a measure of the efficiency of the $A \& E$ department, but also measures the efficiency with which the hospital handles its emergency patients. There is some evidence that the time to admission correlates with the mortality rates of emergency admissions. ${ }^{14}$ The recently published revised Patient's Charter ${ }^{15}$ sets the standard for waiting time to be given a hospital bed. Patients admitted through the $A \& E$ department may expect to be given a bed within three to four hours from the time that the decision is made to admit. However detailed guidance regarding data collection and timing is still awaited.

CONCLUSION

The national performance figures, based on time to immediate assessment, are used to compare the performance of A\&E departments; by implication they suggest that the star rating reflects the standard of care provided by the department. However, this is based on the assumptions that time to immediate assessment is a good indicator of the quality of the assessment, that all departments perform initial assessment to the same standard, and that all departments are measuring time to immediate assessment in the same way. As our study has shown, none of these assumptions is correct.

It is possible that the pressure to assess patients quickly will lead to hasty judgements, purely to satisfy arbitrary numerical standards. Scarce resources are being invested in an activity for which there is no proven clinical benefit.

The star rating system provides no useful information; it does not truly reflect the quality of care and is misleading if used to compare performance between departments. The measurement of time to immediate assessment could be refined, but this would require the investment of significant amounts of time and money. Better indicators of performance of $A \& E$ departments do exist, and the necessary data are already routinely being collected. The new standard of waiting time for a hospital bed is welcomed, but unless data are collected in a standardised way the national performance figures will continue to be uninterpretable.

1 Department of Health. The patient's charter. London: HMSO, 1991.

2 Department of Health. The patient's charter hospital and ambulance services comparative performance guide 19931994. London: Central Office of Information, 1994

3 Estrada EG. Triage systems. Nurs Clin North Am 1981;16:13-24.

4 Wright R. Hostility in accident and emergency departments. Nursing Mirror 1985;161:42-4.

5 Mcmillan JR, Younger MS, DeWine LC. Satisfaction with hospital emergency department as function of patient triage. Health Care Rev 1986;11:21-7.

6 George S, Read S, Westlake L, Williams B, Fraser-Moodie A, Pritty P. Evaluation of nurse triage in a British accident and emergency department. BMf 1992;304:876-8.

7 Bache J. Nurse triage in accident and emergency departments. BMf 1992;304:1378.

8 Cruickshank R. Nurse triage in accident and emergency departments. $B M \mp$ 1992;304:1378.

9 Dale J. Nurse triage in accident and emergency departments. BMF 1992;304:1378.

partments. BMf $1992 ; 304: 1378$.
10 Heyworth J, Hedge $M$. Nurse triage in accident and emergency departments. BMF 1992;304:1378.

11 Porter J. Nurse triage in accident and emergency departments. BMF 1992;304:1378-1379.

12 St George D. Nurse triage in accident and emergency departments. BMF 1992;304:1379.

13 UKCC. Exercising accountability: a framework to assist nurses, midwives and health visitors to consider ethical aspects of professional practice. London: United Kingdom aspects of professional pract

14 Department of Health. UK study into emergency and urgent admissions to hospital. London: HMSO, 1994.

15 Department of Health. The Patient's Charter and you. London: HMSO, 1995. 